\title{
TRANSFORMATION OF SOCIAL STRUCTURE OF THE RUSSIAN SOCIETY IN 1917
}

\author{
Darya A. Kalinina \\ Vyatka State University, Kirov, Russian Federation
}

\begin{abstract}
The article gives an overview of the changes taking place during 1917 in the social structure of Russian society.

Throughout 1917, three independent systems of organization and interaction between social groups had been distinguished: firstly, a fairly clear social division of society, traditional for Russia and preserved until the fall of the monarchy; secondly, a noticeable erosion of the class structure of the population during the period of the Provisional Government and the Soviets, which led to the formalization of class distinctions; thirdly, a new class division of society was observed for the country as one of the natural results of the October Revolution of 1917.

During the period under review, one of the aspects of social inequality was transformed: inequality in the scope of the rights and freedoms of different social groups. Three different models for determining the legal status of the population were identified. In the monarchical period of 1917, there were quite profound differences in the scope of the rights of subjects - the estate principle laid at the heart of inequality. At the stage of the existence of a democratic republic, the class principle of inequality remained, but the difference in the scope of rights and freedoms was actively erased. The Soviet Republic switched to the class principle of social inequality, and deepened the difference in the legal status of classes to the ultimate level. The rate of such changes is completely uncharacteristic of the social structure and is explained by a whole complex of assumptions that provoked an incredibly fast and radical transformation that can be traced throughout 1917.

Key words: social structure, estates, classes, the Russian Empire, the Provisional Government, the Legal Conference, the February Revolution of 1917, the October Revolution of 1917.

Citation. Kalinina D.A. Transformation of Social Structure of the Russian Society in 1917. Vestnik Volgogradskogo gosudarstvennogo universiteta. Seriya 4, Istoriya. Regionovedenie. Mezhdunarodnye otnosheniya [Science Journal of Volgograd State University. History. Area Studies. International Relations], 2017, vol. 22, no. 6, pp. 38-45. (in Russian). DOI: https://doi.org/10.15688/jvolsu4.2017.6.4
\end{abstract}

УДК 94(47).84.2

Дата поступления статьи: 05.07.2017

ББК $63.3(2) 61$

Дата принятия статьи: 10.11.2017

\section{ТРАНСФОРМАЦИЯ СОЦИАЛЬНОЙ СТРУКТУРЫ РОССИЙСКОГО ОБЩЕСТВА В 1917 ГОДУ}

\author{
Дарья Александровна Калинина \\ Вятский государственный университет, г. Киров, Российская Федерация
}

\footnotetext{
Аннотация. В статье приводится обзор происходивших в 1917 г. изменений в социальной структуре российского общества.

На протяжении 1917 г. выделяются три самостоятельные системы организации и взаимодействия между социальными группами: во-первых, достаточно четкое сословное деление общества, традиционное для России и сохранявшееся до падения монархии; во-вторых, заметное размывание сословной структуры населения в период деятельности Временного правительства и Советов, что привело к формализации сословного разграничения; в-третьих, наблюдалось новое для страны классовое деление общества как один из закономерных результатов Октябрьской революции 1917 года.

В исследуемый период прослеживалась трансформация одного из аспектов социального неравенства - неравенства в объеме прав и свобод разных социальных групп. Было выявлено три различных модели
} 
определения правового положения населения. В монархический период 1917 г. наблюдались достаточно глубокие различия в объеме прав подданных, в основе неравенства лежал сословный принцип. На этапе существования демократической республики сохранялся сословный принцип неравенства, однако разница в объеме прав и свобод активно стиралась. Советская республика перешла на классовый принцип социального неравенства и углубила разницу в правовом статусе классов до предельного уровня. Скорость подобных изменений совершенно не свойственна социальной структуре и объясняется целым комплексом предпосылок, спровоцировавших невероятно быструю и радикальную трансформацию, которая прослеживается на протяжении 1917 года.

Ключевые слова: социальная структура, сословия, классы, Российская империя, Временное правительство, Юридическое совещание, Февральская революция 1917 г., Октябрьская революция 1917 г.

Цитирование. Калинина Д. А. Трансформация социальной структуры российского общества в 1917 году // Вестник Волгоградского государственного университета. Серия 4, История. Регионоведение. Международные отношения. - 2017. - Т. 22, № 6. - C. 38-45. - DOI: https://doi.org/10.15688/jvolsu4.2017.6.4

1917 г. в истории нашего государства по праву признается революционным. Череда мощнейших трансформаций, затронувших основные сферы общественной жизни, коренным образом меняла общую картину российской действительности, ломала мироощущение людей. Революционные изменения в политическом устройстве государства, общественных ценностях, правовом поле вынуждали их вольных и невольных участников приспосабливаться к новым реалиям: перестраивать сознание, поведение, выживать и при этом искать свое место в новом мире.

В череде прочих существенной перестройке подвергалась и социальная структура российского общества. Под социальной структурой мы понимаем «сеть упорядоченных и взаимообусловленных связей между элементами социальной системы, в которых отражается способ разделения труда, взаимоотношения социальных групп, характер функционирования социальных институтов, формы социальной организации и социальных действий» $[15$, с. 254]. Для социальной структуры свойственна высокая степень устойчивости, однако и она подвергается изменениям под влиянием революционных процессов. На протяжении 1917 г. мы видим три самостоятельные системы организации взаимодействия между социальными группами.

До февраля 1917 г. в Российской империи существовало исторически устоявшееся традиционное сословное деление общества с вкраплениями классов, ставших одним из проявлений процессов догоняющей модернизации. Сословия как основной элемент в структуре российского общества упоминаются в официальных источниках с XVI в.; под сословиями понимали «разряд людей какого-либо звания, отличающийся от прочих особыми правами и обязанностями» [3, с. 167]. К сословиям в первую очередь стоит отнести дворянство, происхождение и особое положение которого связывали с особыми заслугами предков: «дворянское название есть следствие, истекающее от качества и добродетели начальствовавших в древности мужей, отличивших себя заслугами: чем обращая самую службу в заслугу, приобрели потомству своему нарицание благородное» $[12$, с. 2]. Дворянство делилось на потомственное и личное. Потомственное, то есть передаваемое по наследству, в свою очередь, подразделялось на жалованное или действительное, военное, дворянство, полученное на гражданской службе или на основании награждения орденами, дворянство иностранных родов, титулованное, а также «древние благородные дворянские роды» [12, с. 3]. Сословными признаками обладало и духовенство, к которому относились служители православной, римско-католической, протестантской, армяно-григорианской и армяно-католической конфессий [12, с. 49]. Духовенство делилось на черное монашествующее и белое. Сводом законов о состояниях фиксировалось сословие городских обывателей. В целом под горожанами подразумевались лица, родившиеся или давно живущие в городе, кроме того, лица, имеющие в черте города недвижимость, состоящие в гильдии или цехе, занятые на городской службе. К сословию городских обывателей относили более узкий круг лиц: почетных граждан, купцов, мещан, ремесленников или цеховых [12, 


\section{ПОЛИТИЧЕСКИЕ НАУКИ И РЕГИОНОВЕДЕНИЕ}

c. 59]. К сословием относились также сельские обыватели, в их число входили крестьяне, бывшие заводские, фабричные люди, оружейники, мастеровые, непременные работники, колонисты, половники, башкиры, бывшие вольные люди западных губерний и ряд нерусских народов [12, с. 82]. Перечисленные четыре социальные группы признавались российским законодательством основными, к ним примыкало казачество как особое воинское сословие, однодворцы, бывшие колонисты, водворенные в Таврическую губернию татары, инородцы и иностранцы, проживающие в России.

Положение классов буржуазии и пролетариата законодательно не регулировалось, хотя представления о классах и идущем в государстве процессе классообразования существовали. Известный правовед Н.М. Коркунов в конце XIX в. писал, что «в настоящее время сословия переходят в классы, но эти классы, заменяющие сословия, представляются также опирающимися на единство интересов» [9, с. 287], формирование классов он связывал с «экономической жизнью». Классовой видели структуру российского общества на рубеже XIX-XX вв. сторонники марксистской идеологии В.И. Ленин [10, с. 321], Н.И. Бухарин [2, с. 174-175], А.А. Богданов [1, с. 99] и др. Наиболее обоснованное объяснение полного игнорирования в официальных источниках зарождающейся классовой структуры российского общества дал известный экономист и социолог начала XX в. С.И. Солнцев. Он определил сословие как юридическую категорию, которая нашла отражение в законодательных актах, а класс - как исключительно экономическую категорию [14, с. 370]. В результате классы как самостоятельные социальные группы в экономической действительности растворялись в закрепленных в правовых нормах сословиях.

Февральская революция 1917 г., которая привела к переходу от монархической к республиканской форме правления, внесла некоторые коррективы в структуру российского общества. Уже 3 марта 1917 г. в декларации о создании Временного правительства Временный комитет членов Государственной думы определил основные цели нового высшего органа власти. Среди прочих целью Временного правительства была провозглашена «отмена всех сословных, вероисповедных и национальных ограничений» [4, с. 1], что должно было привести к ликвидации сословий. Однако реальное воплощение на практике принципа юридического равенства столкнулось с препятствием в виде сохранившего свою юридическую силу Свода законов Российской империи, где было закреплено деление общества на четыре сословия с неравным объемом прав.

Для содействия реализации поставленных задач Временное правительство 22 марта 1917 г. создало Юридическое совещание, в компетенцию которого входило представление юридических заключений по отдельным вопросам. Юридическое совещание занималось приведением царского законодательства в соответствие с новыми принципами государственного устройства, означенными в декларации о создании Временного правительства. Суть работы Юридического совещания заключалась в «толковании действующих правовых норм, то есть уяснении и разъяснении их содержания, а также изменении их содержания или отмене в целях приведения в соответствие с новыми правовыми принципами» [11, с. 111]. Было внесено несколько предложений об изменении ряда статей Свода законов Российской империи для устранения сословных различий. Однако в целом Юридическое совещание признало невозможным установление полноценного гражданского равенства из-за необходимости полного пересмотра всего действующего законодательства, и в особенности гражданского и земельного права, имевшего «чисто сословный характер» [7, л. 139].

Таким образом, в период межу февралем и октябрем 1917 г. сохранилась сословная структура общества, состоящая из четырех основных сословий с сохранением внутреннего сословного деления. Деятельность Временного правительства и Юридического совещания привела к сглаживанию сословных различий и размыванию сословных групп. Сформировавшиеся в государстве классы по-прежнему не имели официальной регламентации.

Октябрьская революция 1917 г. и как ее результат новая советская власть внесли кардинальные перемены в систему общественных отношений и сформировали новую струк- 
туру общества, идущую вразрез с традициями социального устройства России. 2 ноября в Декларации прав народов России было провозглашено освобождение рабочих, солдат и крестьян от власти правящих слоев общества: «Раскрепощаются крестьяне от власти помещиков, ибо нет больше помещичьей собственности на землю - она упразднена. Раскрепощаются солдаты и матросы от власти самодержавных генералов, ибо генералы отныне будут выборными и сменяемыми. Раскрепощаются рабочие от капризов и произвола капиталистов, ибо отныне будет установлен контроль рабочих над заводами и фабриками» [5, c. 39]. 11 ноября 1917 г., через пятнадцать дней после ликвидации двоевластия и установления полноты власти Советов, в России было ликвидировано сословное деление общества, отменены сословные привилегии и ограничения, гражданские чины Российской империи $[6$, с. 72$]$. Устанавливалось единое наименование для всего российского населения - гражданин Российской республики. Были устранены все сословные учреждения, их имущество было передано земским и городским самоуправлениям.

Новая социальная структура была официально закреплена в Конституции 1918 г., согласно которой общество подразделялось на класс трудящихся и «имущие классы» [8, c. 244]. К трудящимся новая власть относила рабочих и беднейшую часть крестьянства. Эта общая формулировка тех категорий населения, которые конституцией признавались носителями власти, стоящими на вершине социальной пирамиды нового советского государства, более детально раскрывается при определении круга лиц, наделенных избирательными правами. К трудящемуся классу новая власть относила «всех добывающих средства к жизни производительным и общественно полезным трудом, а также лиц, занятых домашним хозяйством, обеспечивающим для первых возможность производительного труда» $[8$, с. 256]. К ним были причислены рабочие и служащие всех видов и категорий, занятые в промышленности, торговле, сельском хозяйстве, крестьяне и казаки-земледельцы, не пользующиеся наемным трудом с целью извлечения прибыли, солдаты советской армии и флота, а также трудящиеся, потеряв- шие трудоспособность. Под собирательным названием «классы имущих» подразумевались лица, прибегающие к наемному труду с целью извлечения прибыли; лица, живущие на нетрудовой доход, например, проценты с капитала, доходы с предприятий, поступления с имущества; частные торговцы, торговые и коммерческие посредники; монахи и духовные служители церквей и религиозных культов; служащие и агенты бывшей полиции, особого корпуса жандармов и охранных отделений, а также члены царствовавшего в России дома [8, c. 257].

Определение классовой принадлежности было весьма условно и, как правило, зависело от владения собственностью или записи в личных документах о принадлежности к привилегированным сословиям. Объяснение трудности подобной идентификации наиболее полно выражено в исследованиях Т.М. Смирновой, указавшей, что «социальная структура предреволюционной России была крайне сложна и не укладывалась в рамки упрощенного классового подхода, к тому же в конце XIX в. значительно возросла социальная мобильность общества. Различные социальные слои дореволюционной России были тесно переплетены» [13, с. 45]. При всей проблематичности определение принадлежности каждого гражданина к классу трудящихся или «имущих» было принципиально важно для советской власти, так как в государстве был установлен принцип классового неравенства.

По мнению социологов, для любого общества неравенство является неизменной чертой его социальной структуры. Под неравенством мы понимаем «форму дифференциации, при которой отдельные индивиды, социальные группы, слои, классы находятся на разных ступенях вертикальной социальной иерархии и обладают неравными жизненными шансами и возможностями удовлетворения потребностей» $[16$, с. 8$]$. Неравенство является естественным состоянием общества, так как различие в объеме возможностей может зависеть от врожденных и приобретенных качеств личности, от социального окружения, государственной политики и т. д. Одним из видов неравенства является неравенство в правах, оно наглядно отражает иерар- 
хию социальных групп на разных исторических этапах.

На протяжении 1917 г. мы можем наблюдать трансформацию трех моделей социального неравенства, которая отличалась поразительными темпами и глубиной.

В начале $\mathrm{XX}$ в. в условиях сохранения монархической формы правления действующее законодательство устанавливало среди прочих сословный признак разграничения прав и обязанностей подданных. Каждое из четырех основных сословий обладало существенными различиями в объеме полномочий и требований со стороны государства. Наибольшими привилегиями и отсутствием каких-либо обязанностей отличалось дворянское сословие. Дворяне имели право заниматься государственной деятельностью или военной службой «без принуждения к оной» [12, с. 11], поступать на службу в иностранных государствах, являющихся союзниками Российской империи, право торговать и заниматься промышленным производством. Только дворяне могли называться помещиками или вотчинниками, дворянам, не имеющим сыновей, было доступно право передать фамилию с гербом и титулом кому-либо из родственников, они имели исключительное право приобретения собственности на все виды имущества, заключения любых договоров и распоряжения имуществом. Дворяне не могли быть лишены жизни или прав без судебного решения, они освобождались от телесных наказаний, от обязательных городских служб, не платили налогов [12, с. 11-12]. Особой привилегией было право на создание дворянских обществ и собраний, которые выступали органами сословного самоуправления [12, с. 13].

Духовенство обладало сравнительно меньшими привилегиями, к числу которых относилось освобождение от воинской повинности, налогов и сборов, от телесных наказаний, приобретение и отчуждение всеми законными способами земли и жилых построек, заключение договоров [12, с. 49-50]. Особенностью правового положения духовного сословия были существенные ограничения в правах, предусмотренные для черного, или монашествующего, духовенства. Представители черного духовенства не могли приобретать недвижимого имущества, им переставала выплачиваться пенсия за предшествующую военную или гражданскую службу, на них не распространялось наследственное право. Монахам было запрещено заниматься торговлей (исключение делалось для продажи товаров собственного изготовления), быть поручителем или поверенным в делах, не связанных с духовным ведомством [12, с. 51-52]. Подобные ограничения были вызваны, во-первых, священными обетами бедности, послушания, приносимыми при пострижении в монашество; во-вторых, церковной политикой, боровшейся за сохранение образа нравственного и духовного авторитета православной церкви; в-третьих, длительной государственной политикой по установлению экономического контроля над духовенством и присвоению церковного имущества.

Объем прав городских обывателей отличался заметной скромностью по сравнению с положением дворян и дифференциацией в зависимости от разновидности групп горожан. Так, почетные граждане освобождались от телесных наказаний и обладали сословным самоуправлением, купцы также освобождались от телесных наказаний, имели право заниматься торговлей и промышленным производством, мещане обладали правом перехода в купеческое сословие при соблюдении ряда условий, могли заключать договор подряда с Казной [12, с. 65, 68, 72]. Сельские обыватели обладали равными со всеми сословиями личными правами, могли приобретать в собственность и отчуждать движимое и недвижимое имущество, правда, последнее с особыми ограничениями [12, с. 83].

В целом неравенство в правах, совпадающее с сословным делением российского общества, было традиционным, а следовательно, привычным явлением, естественным фоном повседневной действительности Российской империи начала $\mathrm{XX}$ века. Объем прав сословий подвергался изменениям, но они были редким явлением. Только в период Первой российской революции произошло существенное увеличение прав и свобод подданных за счет дарования в равной мере всему населению права неприкосновенности личности, свободы совести, слова, собраний и союзов. Декларированные Манифестом 17 октября 1905 г. политичес- 
кие свободы были ограничены при их практическом применении.

Февральская революция и приход к власти Временного правительства и Советов спровоцировали заметные изменения в правовом положении российского населения. Новая власть провозгласила введение в стране в равной мере для всего населения «свободы слова, печати, союзов, собраний и стачек с распространением политических свобод на военнослужащих в пределах, допускаемых военно-техническими условиями... всеобщее равное тайное избирательное право» $[4$, с. 1]. В отличие от царского правительства, новый орган государственной власти пошел по пути более полной реализации указанных свобод на практике. Подобная политика привела, вопервых, к расширению объема прав и свобод российского общества, во-вторых, к постепенному размыванию различий в правовом статусе сохранившихся сословий, превращению их в относительно формальный признак социального неравенства. Декларированное Временным правительством устранение сословных различий натолкнулось на проблему в виде сохранившего свою юридическую силу основного массива дореволюционного законодательства, целиком основанного на сословном неравенстве. Создать новый свод законов, основанный на демократических принципах равенства, Временное правительство не смогло, кроме того, подобное законотворчество выходило за рамки компетенции этого исполнительно-распорядительного органа власти.

Октябрьская революция и установление советской власти так и не стали предпосылкой установления равенства в правах для всех социальных групп. Ликвидировав сословия, новая власть установила классовое деление общества и перешла на принцип классового неравенства в политике определения правового статуса населения. Еще до принятия Конституции 1918 г. советская власть практиковала ущемление в правах для представителей «класса имущих». Для последних устанавливались более суровые наказания за уголовные преступления, для нетрудящихся вводились ограничения в назначении на руководящие должности, устанавливались узкие квоты для получения высшего образования и т. д. [13, с. 62].
С принятием Конституции 1918 г. классовое неравенство достигло своего пика, и в молодом советском обществе появляется категория лишенцев. Советская власть утвердила новое правило: «руководствуясь интересами рабочего класса в целом, Российская Социалистическая Федеративная Советская Республика лишает отдельных лиц и отдельные группы прав, которые используются ими в ущерб интересам социалистической революции» $[8$, с. 246]. За классом трудящихся закреплялись свобода совести, свобода выражения мнений, собраний, союзов, право на полное, всестороннее, бесплатное образование, право избирать и быть избранным в Советы [8, c. 245-246, 257].

Принцип классового неравенства был революционным для своего времени. Соотношение прав слоев населения, их статус в социальной иерархии были перераспределены в обратном порядке. Подобная социальная политика стала фундаментом последующих государственных преобразований, касающихся определения прав и обязанностей в советском обществе.

Итак, на протяжении 1917 г. происходили заметные изменения в структуре российского общества, эти процессы были вызваны как объективными предпосылками, к которым следует отнести особенности экономического и духовного развития населения, так и субъективными условиями, вызванными политикой сил, стоящих во главе государства. Скорость и радикальность происходящих изменений в организации взаимодействия между социальными группами дает возможность предположить, что подобные трансформации требовали от современников революционных событий 1917 г. сосредоточения значительных сил для быстрого приспособления к новым реалиям.

\section{СПИСОК ЛИТЕРАТУРЫ}

1. Богданов, А. А. Эмпирионзм : статьи по философии / А. А. Богданов. - М. : Республика, 2003.$400 \mathrm{c}$.

2. Бухарин, Н. И. Общество. Классы и классовая борьба / Н. И. Бухарин // Социология в России XIX - начала XX веков : Общество. Законы исто- 


\section{ПОЛИТИЧЕСКИЕ НАУКИ И РЕГИОНОВЕДЕНИЕ}

рии. Прогресс. Цели и нормы жизни : Тексты / под ред. В. И. Добренькова. - М. : Изд-во Междунар. ун-та бизнеса и упр., 2001. - С. 174-175.

3. Виноградов, В. В. Сословие / В. В. Виноградов // Сословная структура постсоветской России / С. Г. Кордонский. - М. : Ин-т Фонда «Общественное мнение», 2008. - С. 163-167.

4. Декларация Временного правительства о его составе и задачах // Вестник Временного правительства. - 1917. - № 1 (46). - С. 1.

5. Декларация прав народов России от 2(15) ноября 1917 г. // Декреты Советской власти. Т. І. М. : Гос. изд-во полит. лит., 1957. - С. 39-41.

6. Декрет об уничтожении сословий и гражданских чинов от 11(24) ноября 1917 г. // Декреты Советской власти. Т. І. - М. : Гос. изд-во полит. лит., 1957.- С. 72.

7. Журналы заседаний Юридического совещания при Временном правительстве за 23 мая - 8 августа 1917 г. Подлинники. Т. 2 // Государственный архив Российской Федерации (ГАРФ). - Ф. 1792. Оп. 1. - Д. 3. -247 л.

8. Конституция (Основной закон) Российской Социалистической Федеративной Советской республики : принята V Всерос. съездом Советов 10 июля 1918 г. // Очерк истории Советской Конституции / Ю. С. Кукушкин, О. И. Чистяков. - М. : Политиздат, 1987. - С. 239-261.

9. Коркунов, Н. М. Лекции по общей теории права / Н. М. Коркунов. - 2-е изд. - М. : РОССПЭН, 2010. $-520 \mathrm{c}$.

10. Ленин, В. И. Что такое «друзья народа» и как они воюют против социал-демократов (Ответ на статьи «Русского богатства» против марксистов) / В. И. Ленин // Полн. собр. соч. Т. 1 / В. И. Ленин. 5-е изд. - М. : Полит. лит., 1967. - С. 125-346.

11. Редких, С. В. Процедура нормоконтроля в деятельности Юридического совещания Временного правительства / С. В. Редких // Вестник Челябинского государственного университета. - 2009. Вып. 21, № 31. - С. 111-114.

12. Свод законов о состояниях. Изд. 1889 г. // Свод законов Российской империи. Неофициальное издание. Т. 9. - СПб. : Рус. кн. товарищество «Деятель», 1912. - С. 1-100.

13. Смирнова, Т. М. «Бывшие люди» в социальной структуре и повседневной жизни советского общества, 1917-1936 гг. : дис. ... д-ра ист. наук / Смирнова Татьяна Михайловна. - М., 2009. - 300 с.

14. Солнцев, С. И. Общественные классы / С. И. Солнцев. - М. : АСТ : Астрель, 2007. -635 с.

15. Философская энциклопедия. Т. 5 / под ред. Ф. В. Константинова. - М. : Сов. энцикл., 1970. - 740 с.

16. Шкаратан, О. И. Социология неравенства. Теория и реальность / О. И. Шкаратан. - М.: Изд. дом Высшей школы экономики, 2012. - 526 с.

\section{REFERENCES}

1. Bogdanov A.A. Empirionzm: Statyi po filosofii [Empirionism: Articles on Philosophy]. Moscow, Respublika Publ., 2003. 400 p.

2. Bukharin N.I. Obshchestvo. Klassy i klassovaya borba [Society. Classes and Class Struggle]. Dobrenkov V.I., ed. Sotsiologiya v Rossii $X I X$-nachala XX vekov. Obshchestvo. Zakony istorii. Progress. Tseli i normy zhizni. Teksty [Sociology in Russia of the $19^{\text {th }}-$ early $20^{\text {th }}$ Centuries. Society. Laws of History. Progress. Goals and Standards of Life. Texts]. Moscow, Izd-vo Mezhdunar. univ. biznesa i upr., 2001, pp. 174-175.

3. Vinogradov V.V. Soslovie [Estate]. Kordonskiy S.G., ed. Soslovnaya struktura postsovetskoy Rossii [Class Structure of Post-Soviet Russia]. Moscow, Institut Fonda "Obshchestvennoe mnenie", 2008, pp. 163-167.

4. Deklaratsiya Vremennogo pravitelstva o ego sostave i zadachakh [Declaration of the Provisional Government on Its Composition and Tasks]. Vestnik Vremennogo pravitelstva [Bulletin of the Provisional Government], 1917, no. 1 (46), p. 1.

5. Deklaratsiya prav narodov Rossii ot 2(15) noyabrya 1917 g. [Declaration of the Rights of the Peoples of Russia of November 2 (15), 1917]. Dekrety Sovetskoy vlasti. T. I. [Decrees of the Soviet Government. Vol. I]. Moscow, Gos. izd-vo polit. lit., 1957, pp. 39-41.

6. Dekret ob unichtozhenii sosloviy i grazhdanskikh chinov ot 11(24) noyabrya $1917 \mathrm{~g}$. [Decree on the Abolition of Estates and Civil Ranks of 11 (24) November 1917]. Dekrety Sovetskoy vlasti. T. I. [Decrees of the Soviet Government. Vol. I]. Moscow, Gos. izd-vo polit. lit., 1957, p. 72.

7. Zhurnaly zasedaniy Yuridicheskogo soveshchaniya pri Vremennom pravitelstve za 23 maya -8 avgusta 1917 g. Podlinniki. T. 2. [Journals of the Sessions of the Legal Meeting under the Provisional Government for May 23 - August 8, 1917. Original Copies. Vol. 2]. Gosudarstvennyy arkhiv Rossiyskoy Federatsii [State Archives of the Russian Federation], F. 1792, Op. 1, D. 3.247 p.

8. Konstitutsiya (Osnovnoy zakon) Rossiyskoy Sotsialisticheskoy Federativnoy Sovetskoy respubliki. Prinyata V Vserossiyskim syezdom Sovetov 10 iyulya 1918 g. [Constitution (Basic Law) of the Russian Socialist Federative Soviet Republic. Adopted by the VAll-Russian Congress of Soviets on July 10, 1918]. Kukushkin Yu.S., Chistyakov O.I. Ocherk istorii Sovetskoy Konstitutsii [Essay on the History of the Soviet Constitution]. Moscow, Politizdat Publ., 1987, pp. 239-261.

9. Korkunov N.M. Lektsii po obshchey teorii prava [Lectures on the General Theory of Law]. Moscow, ROSSPEN Publ., 2010. 520 p. 
10. Lenin V.I. Chto takoe «druzya naroda» i kak oni voyuyut protiv sotsial-demokratov (Otvet na statyi «Russkogo bogatstva» protiv marksistov) [Who Are "Friends of the People" and How They Are Fighting against the Social Democrats (Response to the articles of "Russian Wealth" against Marxists)]. Lenin V.I. Poln. sobr. soch. T. 1. [Lenin V.I. Complete Collection of Works. Vol. 1]. Moscow, Polit. lit. Publ., 1967, pp. 125-346.

11. Redkikh S.V. Protsedura normokontrolya v deyatelnosti Yuridicheskogo soveshchaniya Vremennogo pravitelstva [The Procedure of Normative Control in the Activity of the Legal Meeting of the Provisional Government]. Vestnik Chelyabinskogo gosudarstvennogo universiteta [Journal of Chelyabinsk State University], 2009, iss. 21, no. 31 (169), pp. 111-114.

12. Svod zakonov o sostoyaniyakh. Izd. $1889 \mathrm{~g}$. [Code of Laws on States. Edition of 1889]. Svod zakonov Rossiyskoy imperii. Neofitsialnoe izdanie
[Code of laws of the Russian Empire. Informal Publication. Vol. 9]. Saint Petersburg, Russkoe kn. tov. "Deyatel", 1912, pp. 1-100.

13. Smirnova T.M. «Byvshie lyudi»v sotsialnoy strukture $i$ povsednevnoy zhizni sovetskogo obshchestva: 1917-1936 gg.: dis. ... d-ra ist. nauk ["Former People" in the Social Structure and Daily Life of Soviet Society: 1917-1936. Dr. hist. sci. diss.]. Moscow, 2009. 300 p.

14. Solntsev S.I. Obshchestvennye klassy [Social Classes]. Moscow, AST: Astrel Publ., 2007. 635 p.

15. Konstantinov F.V., ed. Filosofskaya Entsiklopediya. T. 5 [Philosophical Encyclopedia. Vol. 5]. Moscow, Sovetskaya entsiklopediya Publ., 1970. 740 p.

16. Shkaratan O.I. Sotsiologiya neravenstva. Teoriya $i$ realnost [Sociology of Inequality. Theory and Reality]. Moscow, Izd. dom Vysshey shkoly ekonomiki, 2012.526 p.

\section{Information about the Author}

Darya A. Kalinina, Candidate of Sciences (History), Associate Professor, Department of Theory and History of State and Law, Vyatka State University, Moskovskaya St., 36, 610000 Kirov, Russian Federation, Kalininadarja@mail.ru, https://orcid.org/0000-0002-6938-7851

\section{Информация об авторе}

Дарья Александровна Калинина, кандидат исторических наук, доцент кафедры теории и истории государства и права, Вятский государственный университет, ул. Московская, 36, 610000 г. Киров, Российская Федерация, Kalininadarja@mail.ru, https://orcid.org/0000-0002-6938-7851 